\author{
Metal Injection Molding 공정으로 제조된 W-7Ni-3Fe 텅스텐 중합금의 \\ 미세조직 및 기계적 특성에 미치는 열처리의 영향 \\ 윤성준 ${ }^{1} \cdot$ 주연아 ${ }^{1} \cdot$ 윤태식 ${ }^{2} \cdot$ 이기안 ${ }^{1, *}$ \\ 1인하대학교 신소재공학과 \\ 2베스너(주)
}

\title{
Effect of Heat Treatment on the Microstructure and Mechanical Properties of W-7Ni-3Fe Tungsten Heavy Alloy Manufactured by Metal Injection Molding Process
}

\author{
Seong-June Youn ${ }^{1}$, Yeun-Ah Joo ${ }^{1}$, Tae-Shik Yoon ${ }^{2}$, and Kee-Ahn Lee, ${ }^{1, *}$ \\ ${ }^{I}$ Department of Materials Science and Engineering, Inha University, Incheon 22212, Republic of Korea \\ ${ }^{2}$ Bestner Co., Eumseong 27623, Republic of Korea
}

\begin{abstract}
This study investigated the microstructure and room temperature mechanical properties of W-7Ni$3 \mathrm{Fe}$ (wt\%) tungsten heavy alloy (as-fabricated) which was manufactured by metal injection molding (MIM). To identify the effect of heat treatment on the W-7Ni-3Fe alloy, its properties were compared after heattreatment $\left(1,100^{\circ} \mathrm{C}\right.$ for 1 hour $)$ in vacuum atmosphere. The initial microstructural observations confirmed that both the as-fabricated and heat-treated specimens were composed of $\mathrm{W}$ phase and $\gamma(\mathrm{Ni}, \mathrm{Fe})$ phase. Vickers hardness measurements were $363.7 \mathrm{Hv}$ for the as-fabricated specimen and $387.2 \mathrm{Hv}$ for the heat-treated specimen. Room temperature tensile strength was tested, and the yield strength of the as-fabricated and heattreated specimens were 698.3 and $714.0 \mathrm{MPa}$, and the ultimate tensile strengths were 760.8 and $960.0 \mathrm{MPa}$, respectively. The elongation of the two materials was $2.4 \%$ (as-fabricated) and $20.3 \%$ (heat-treated). It was found that additional heat treatment after MIM significantly improved the alloy's mechanical properties. In addition, fracture surface observation results confirmed that the main crack propagated along the interface between the spherical $\mathrm{W}$ phase and $\gamma(\mathrm{Ni}, \mathrm{Fe})$ phase in the as-fabricated specimen, and traversed the $\mathrm{W}$ phase in the heat-treated specimen. Based on the above findings, this study also discusses the fracture mechanisms of tungsten heavy alloy manufactured with MIM.
\end{abstract}

(Received August 9, 2018; Accepted August 31; 2018)

Keywords: W-7Ni-3Fe, metal injection molding, tungsten heavy alloy, microstructure, tensile properties

\section{1. 서 론}

$\mathrm{W}-7 \mathrm{Ni}-3 \mathrm{Fe}(\mathrm{wt} \%)$ 합금은 W-Ni-Fe계 텅스텐 중합금 중 하나로 $\gamma$-matrix 내 구형의 $\mathrm{W}$ 입자가 분포되어 있는 조직 을 가진 2상 복합체이다. 이 합금은 높은 밀도를 가지며 우수한 연성, 강도, 인성 및 내식성을 갖는 소재로 rotor, valance weight, kinetic energy penetration 등 고밀도, 고 강도가 요구되는 분야에서 사용되고 있다 [1-4]. 그러나

*Corresponding Author: Kee-Ahn Lee [Tel: +82-32-860-7532, E-mail: keeahn@inha.ac.kr ] Copyright (c) The Korean Institute of Metals and Materials
W-7Ni-3Fe 텅스텐 중합금은 우수한 기계적 특성에도 불구 하고 난가공성 소재로 형상 제어가 어렵다는 단점을 지닌 다 [5].

금속 사출 성형(metal injection molding, MIM) 공정은 플라스틱 사출 성형법과 분말 야금 기술이 조합된 분말 야 금 성형 기술이다. MIM 공정은 $20 \mu \mathrm{m}$ 이하의 미세한 분 말과 결합제를 혼합하여 사출 성형하고 탈지 반응을 통해 결합제를 제거한 뒤 소결 단계를 걸쳐 고밀도의 제품을 생 성하는 공정이다. 이 공정은 정밀 주조 공정 및 다이 캐스 팅 공정과 비교하여 치수정밀도가 높아 난가공재의 경우에 도 후 가공처리 없이 정밀한 형상의 부품으로 제조할 수 
있으며 대량 생산이 가능하다는 장점을 가지고 있다 [5-8].

현재까지 W-7Ni-3Fe 합금은 주로 액상 소결법으로 제조 되어 왔다. 그러나 액상 소결 법으로 $\mathrm{W}-7 \mathrm{Ni}-3 \mathrm{Fe}$ 합금을 제조할 경우 $1460{ }^{\circ} \mathrm{C}$ 이상의 높은 온도에서 소결을 수행 해야 한다는 공정 상의 제한과 형상 왜곡이 쉽게 발생할 수 있다는 문제점이 있다 $[9,10]$. 이에 따라 $\mathrm{W}-7 \mathrm{Ni}-3 \mathrm{Fe}$ 합금의 형상을 비교적 쉽게 제어하여 적용 범위를 넓히고 자 MIM 공정을 통해 W-7Ni-3Fe 합금을 제조하려는 시 도가 이루어지고 있다. 현재 MIM 공정으로 제조된 W$7 \mathrm{Ni}-3 \mathrm{Fe}$ 합금 소재는 미세조직 및 기계적 특성에 미치는 고에너지 볼 밀링(high energy ball milling, HEBM) [11-14]에 대한 연구가 일부 보고되었다. 그러나 이러한 연 구 결과의 대부분은 미세조직, 기계적 특성의 단순 제시에 국한되어 있으며, 열처리에 의한 특성 향상과 미세조직의 변형 거동을 연계 해석한 연구는 미비한 상태이다.

본 연구에서는 $\mathrm{MIM}$ 공정을 이용하여 $\mathrm{W}-7 \mathrm{Ni}-3 \mathrm{Fe}$ 합금 을 제조하고 이에 대한 미세조직 및 상온 기계적 특성을 조사하였다. 이와 함께 진공 분위기에서 열처리를 수행하 여 미세조직 및 기계적 특성에 미치는 열처리의 영향을 알 아보고자 하였다. 또한 MIM 공정으로 제조된 W-7Ni-3Fe 합금 소재의 파단면 관찰을 통해 변형 거동에 대해서 고찰 해보았다.

\section{2. 실험 방법}

본 연구에서 세 종류의 순수 분말들( $\mathrm{W}, \mathrm{Ni}, \mathrm{Fe}$ 분말)을 사용하였으며 사용한 분말을 그림 1 에 도시하였다. 본 연 구에서 사용된 $\mathrm{W}, \mathrm{Ni}, \mathrm{Fe}$ 분말들의 평균 분말 입자 크기 (average powder particle size)는 각각 $1.70,4.94$, $2.39 \mu \mathrm{m}$ 로 측정되었다. $\mathrm{MIM}$ 공정을 통해 $\mathrm{W}-7 \mathrm{Ni}-3 \mathrm{Fe}$ 합 금을 제조하기 위해서 상기 분말들을 조성에 맞추어 정량 하고 QM-1 유성형 볼 밀을 이용하여 기계적 합금화 (mechanical alloying, MA)하였다. 그 후 MA 처리된 분 말들을 결합제와 혼합하고 사출 성형을 수행한 후, 탈지 및 소결 단계를 거쳤다. 소결 단계에서는 수소 분위기에서 $1,420{ }^{\circ} \mathrm{C}$ 로 1 시간 동안 소결을 수행하였으며 최종적으로는 ASTM E8 규격의 판상 시편(as-fabricated)을 제조하였다. 추가적으로 $\mathrm{MIM}$ 공정을 통해 제조된 W-7Ni-3Fe (wt\%) 합금에 미치는 열처리의 영향을 알아보기 위해 시편 소재 에 대해 추가로 진공 분위기에서 $1,100^{\circ} \mathrm{C}$ 로 1 시간 동안 열처리를 수행한 뒤 질소 가스를 이용하여 퀜칭하였다. 이 후 초기 제조 소재를 초기 소재로 열처리 한 소재를 열처 리된 소재로 명명하고자 한다.
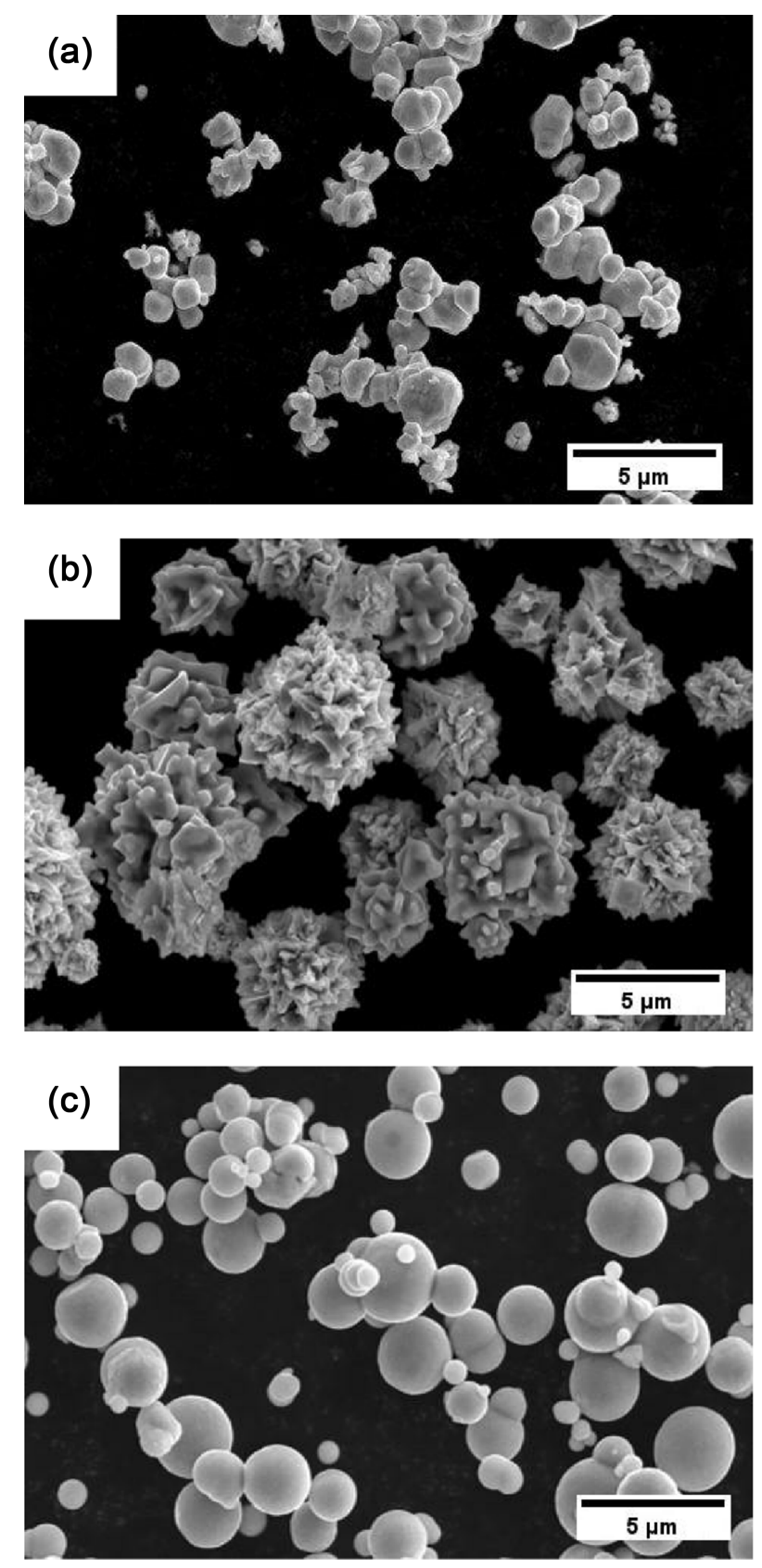

Fig. 1. SEM observation results for initial powder feedstocks; (a) W powder, (b) Ni powder, and (c) Fe powder.

제조된 소재들의 상 분석을 위하여 주사전자현미경 (scanning electron microscopy, SEM, Tescan, VEGA II LMU), 에너지 분광기(energy dispersive spectroscopy, $\mathrm{EDS})$, 엑스선 회절 분석기(X-ray diffraction, $\mathrm{XRD}$, Rigaku XRD Ultima IV), 전자빔미세분석기(electron probe X-ray microanalyzer, EPMA, EPMA-1600)를 사용하였다. 기공도 를 측정하기 위하여 기계적 연마를 실시한 뒤에 SEM 이미 
지와 이미지 분석기를 사용하여 20 회 측정 후 평균 값을 구하였다.

기계적 특성 평가를 위해 비커스(Vickers) 경도 및 상온 인장 시험을 수행하였다. 경도는 비커스 경도기 AVK$\mathrm{C} 100$ 를 이용하여 12 회 측정 후 평균 값을 구하였다. 인장 시험은 인장 시험기 Instron-8501을 이용하여 변형률 속도 가 $10^{-3} / \mathrm{s}$ 가 되도록 설정한 뒤 소재 별로 3 회 실시하였다. 인장 시험 후 소재의 변형 및 파괴 거동을 알아보기 위해 전계방출형 주사전자현미경(field emission scanning electron microscopy, S-4300, FE-SEM)을 이용하여 파면 을 관찰하였다.

\section{3. 결과 및 고찰}

초기 소재 및 열처리된 소재의 XRD 상 분석 결과를 그림 2에 나타내었다. 두 소재 모두 $\mathrm{W}$ 상과 $\gamma(\mathrm{Ni}, \mathrm{Fe})$ 상으로 구성된 2 상 복합 소재(composite)임을 알 수 있 었으며, $\mathrm{W}$ 상과 $\gamma(\mathrm{Ni}, \mathrm{Fe})$ 상 이외의 다른 상은 검출되지 않았다. 즉 추가적인 열처리를 수행함에도 불구하고 상 변 화가 일어나지 않는 것이 확인되었다.
그림 3은 $\mathrm{MIM}$ 공정으로 제조된 $\mathrm{W}-7 \mathrm{Ni}-3 \mathrm{Fe}$ 합금의 $\mathrm{SEM} / \mathrm{EDS}$ 관찰 결과이다. 여기서 (a)는 초기 소재, (b)는 열처리된 소재이다. 그림 3을 통해 두 소재 모두 조대한 결함은 관찰되지 않았으며 구형의 밝은 영역과 어두운 영 역으로 구성되어 있는 것을 확인 할 수 있었다. 각각의 영

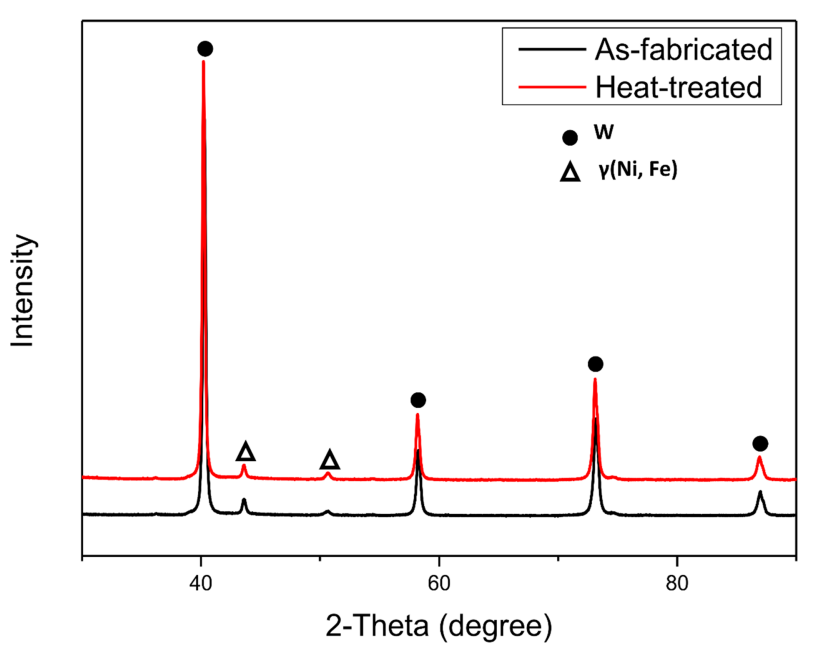

Fig. 2. XRD phase analysis results for as-fabricated and heat-treated W-7Ni-3Fe alloys.
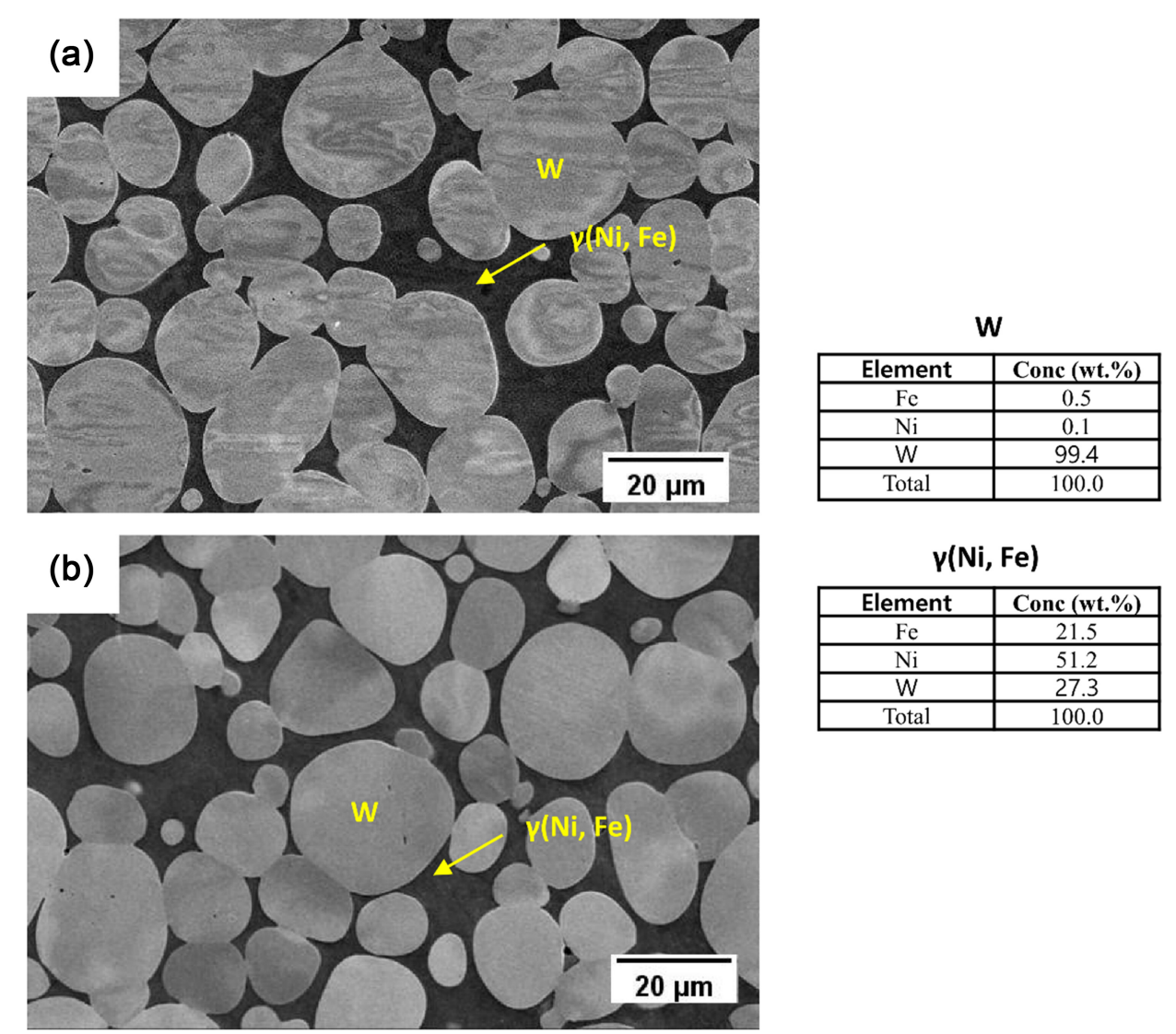

$\gamma(\mathrm{Ni}, \mathrm{Fe})$

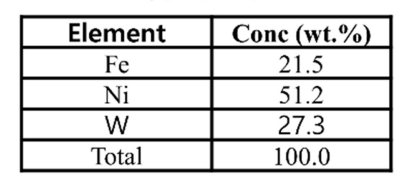

Fig. 3. SEM/EDS microstructural observation results for (a) as-fabricated and (b) heat-treated W-7Ni-3Fe alloys. 
W

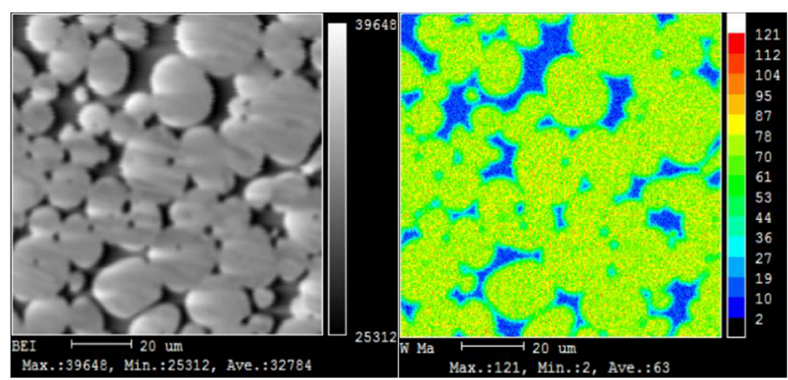

$\mathrm{Ni}$

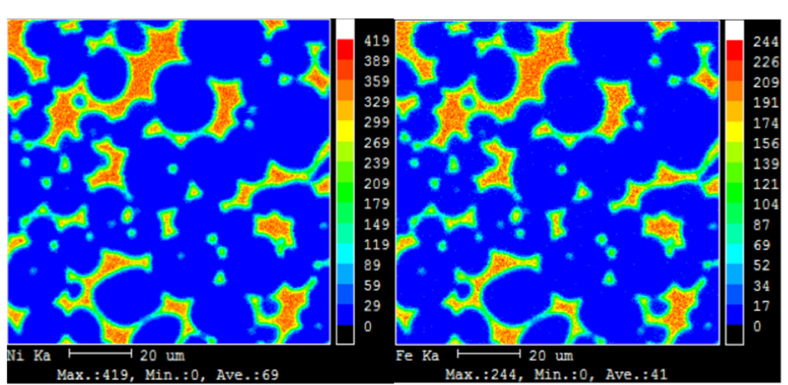

(a)

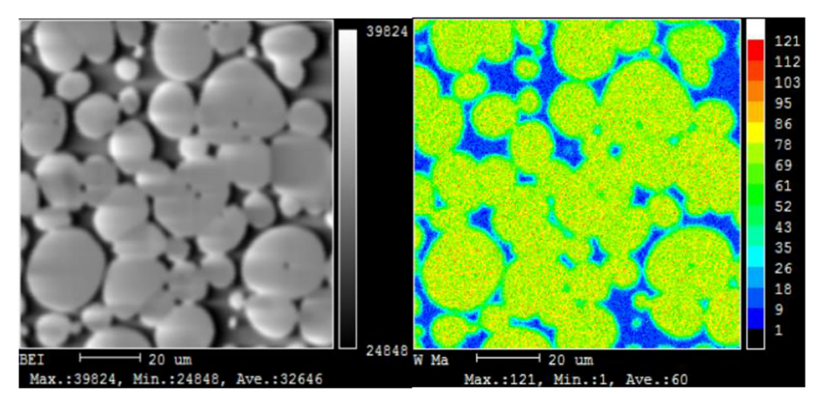

$\mathrm{Ni}$

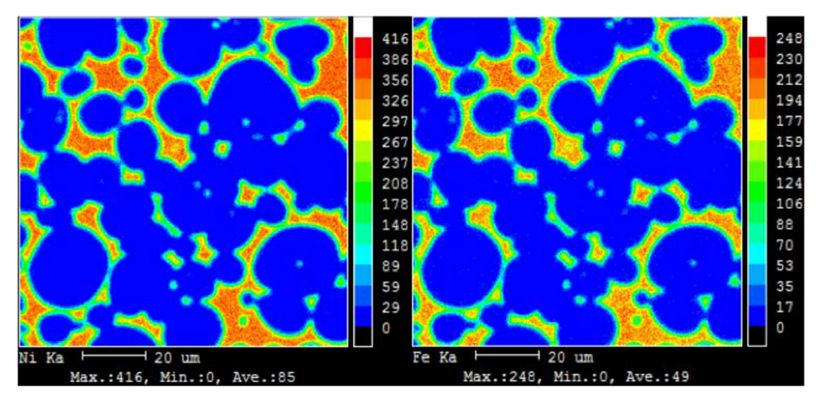

(b)

Fig. 4. EPMA analysis results for (a) as-fabricated and (b) heattreated $\mathrm{W}-7 \mathrm{Ni}-3 \mathrm{Fe}$ alloys.

역에 대해 EDS 분석을 수행한 결과 상대적으로 밝은 영 역은 $\mathrm{W}$ 원소가 많이 검출되는 $\mathrm{W}$ 상임을, 상대적으로 어 두운 영역은 $\mathrm{Ni}, \mathrm{Fe}$ 원소가 많이 검출되는 $\gamma(\mathrm{Ni}, \mathrm{Fe})$ 상 임을 알 수 있었다. 추가적으로 각 상들의 분율을 정량적
으로 측정해보았다. 그 결과 초기 소재와 열처리된 소재의 $\mathrm{W}$ 상 분율은 각각 $81.57 \%, 81.38 \%$ 로 나타났으며 기공도 는 각각 $0.06 \%, 0.04 \%$ 로 확인되었다. 이를 통해 진공 분위 기에서 열처리를 수행함에도 불구하고 상 분율이나 기공도 는 크게 변하지 않는 것을 알 수 있었다.

두 소재의 성분 분포 차이를 더욱 자세히 알아보고자 EPMA 분석을 수행하였으며 그 결과를 그림 4에 도시하였 다. EPMA 분석 결과, 두 소재 모두 기지 영역에서는 $\mathrm{Ni}$, $\mathrm{Fe}$ 원소가 균일하게 분포하고 있는 것을, 구형의 $\mathrm{W}$ 상 영 역에서는 $\mathrm{W}$ 원소가 분포되어 있는 것을 확인할 수 있었 다. 한편 W-Ni-Fe 텅스텐 중합금의 경우 각 원소들의 함 량, 소결 온도 및 시간에 따라 합금의 기계적 특성을 저하 시키는 $\mu$ 상 $(\mathrm{W}$ 과 $\mathrm{Fe}$ 로 이루어진 금속간 화합물)이 생성될 수 있다고 보고되고 있다 [15]. 그러나 상기 미세조직 관찰 결과들을 통해 본 연구에서 사용된 소재들의 경우 $\mu$ 상가 존 재하지 않는 건전한 소재임을 알 수 있었다.

$\mathrm{W}-7 \mathrm{Ni}-3 \mathrm{Fe}$ 합금의 열처리에 따른 기계적 특성을 평가하 였다. 먼저 비커스 경도 측정 결과 초기 소재 및 열처리된 소재의 경도는 각각 $363.7,387.2 \mathrm{Hv}$ 로 측정되어 열처리 후 경도 값이 증가하는 경향을 나타내었다. 초기 소재 및 열처리된 소재의 경도 값을 타 공정으로 제조된 동일 조성 (W-7Ni-3Fe)합금의 경도 값과 비교해보았다. 비교 소재로 는 W-7Ni-3Fe 합금에 주로 적용되는 액상소결(liquid phase sintering, LPS) [16] 공정과 상온 가공(cold work) [17] 공정으로 제조된 W-7Ni-3Fe 합금이 있으며, 각각의 공정들(액상소결, 상온가공)로 제조된 $\mathrm{W}-7 \mathrm{Ni}-3 \mathrm{Fe}$ 합금의 경도 값은 각각 $270 \mathrm{Hv}, 380 \mathrm{Hv}$ 로 보고되었다. 이를 통해 본 연구에서 제조된 초기 소재 $(363.7 \mathrm{Hv})$ 및 열처리된 소재 $(387.2 \mathrm{Hv})$ 의 경도 값은 타 공정으로 제조된 W-7Ni$3 \mathrm{Fe}$ 합금의 경도 값과 유사하거나 비교적 우수한 수준임을 알 수 있었다.

그림 5 는 초기 소재 및 열처리된 소재의 상온 인장 시 험 결과를 통해 얻은 응력 변형률 곡선을 나타낸 것이다. 인장 시험 결과 초기 소재와 열처리된 소재의 항복 강도는 각각 $698.3,714.0 \mathrm{MPa}$ 로 측정되었으며 최대 인장 강도는 각각 $760.8,960.0 \mathrm{MPa}$ 로 나타났다. 또한 초기 소재와 열 처리된 소재의 연신율은 각각 $2.4 \%, 20.3 \%$ 로 측정되었다. 이를 통해 초기 소재와 열처리된 소재의 상 분율 및 기공 도가 유사함에도 불구하고 열처리 이후 경도, 강도뿐만 아 니라 연신율까지 큰 폭으로 증가함을 알 수 있었다.

앞서 제시한 초기 소재와 열처리된 소재의 상온 인장 특 성을 타 공정으로 제조된 W-7Ni-3Fe 합금의 상온 인장 특성과 비교해보았으며 그 결과를 표 1에 나타내었다. 비 


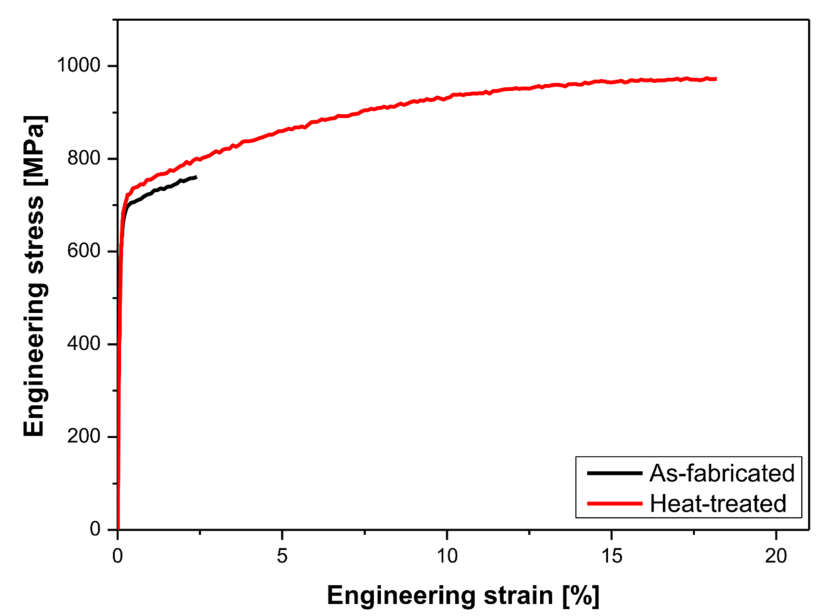

Fig. 5. Tensile stress-strain curves for as-fabricated and heattreatment $\mathrm{W}-7 \mathrm{Ni}-3 \mathrm{Fe}$ alloys.

교재로는 액상소결 [16]을 포함하여 마이크로파 소결 (microwave sintering) [18]과 같은 분말 야금 공정 및 상 온 가공 [17], 냉간 등방압 가압법(cold isostatic pressing, CIP) [19], 젤캐스팅 (gelcasting) [19] 공정으로 제조된 W$7 \mathrm{Ni}-3 \mathrm{Fe}$ 합금이다. 여기에서 동일한 조성임에도 불구하고 제조 공정이 변화함에 따라 $\mathrm{W}$ 상의 크기 및 분율이 달라 질 수 있으나 이러한 상관 관계는 여기서 다루지 않았으며, 각 공정의 최적 조건에 대한 기계적 특성만을 비교하였다 . 표 1 를 통하여 타 공정으로 제조된 $\mathrm{W}-7 \mathrm{Ni}-3 \mathrm{Fe}$ 합금의 항복 강도는 $590-630 \mathrm{MPa}$ 수준임을, 최대 인장 강도는 810-920 MPa 수준임을 알 수 있다. 이를 통해 본 연구에 서 제조된 초기 소재는 타 공정과 유사한 기계적 특성을 지닌 것을, 열처리된 소재는 타 공정에 비해 우수한 기계 적 특성을 나타내는 것을 알 수 있다.

$\mathrm{W}-7 \mathrm{Ni}-3 \mathrm{Fe}$ 합금들의 열처리에 따른 변형 거동 차이를 알아보고자 인장 시험 후 파단면을 관찰하였으며 그 결과 를 그림 6에 나타내었다. 먼저 파단면을 저 배율로 관찰한
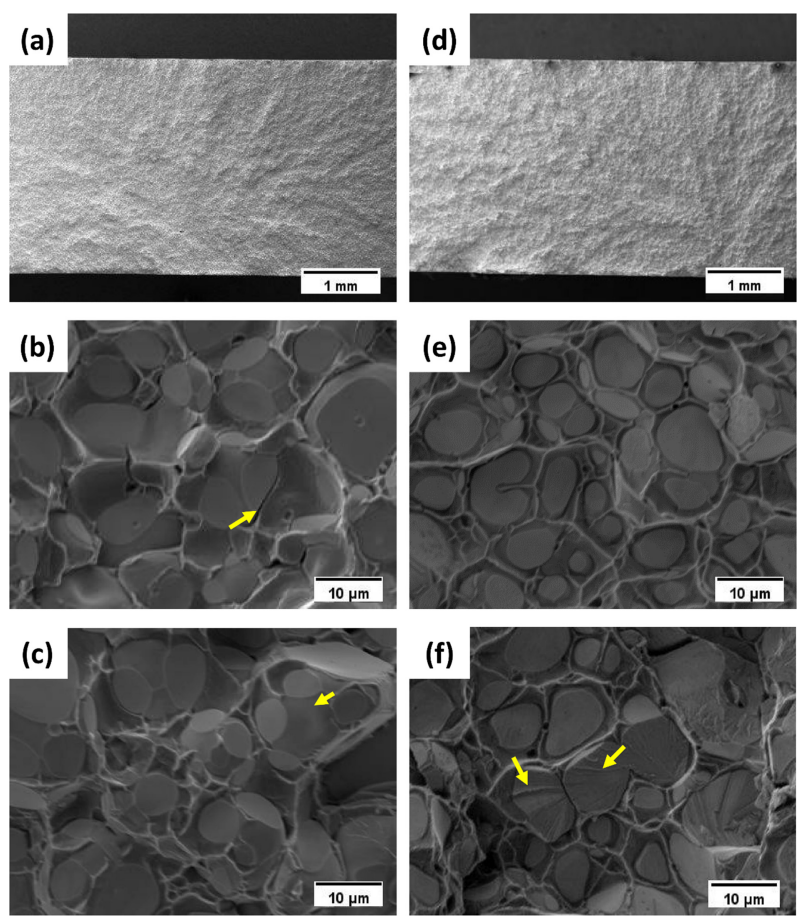

Fig. 6. SEM fractography observation results: $(a, b, c)$ as-fabricated and $(\mathrm{d}, \mathrm{e}, \mathrm{f})$ heat-treated specimens after tensile tests.

결과 그림 6(a), (d) 두 소재 모두 조대한 결함은 존재하 지 않았다. 파단면을 고 배율로 관찰한 결과 그림 6(c), (f) 초기 소재와 열처리된 소재들에서 공통적으로 $\gamma(\mathrm{Ni}, \mathrm{Fe})$ 상에서 연신된 특징을 확인 할 수 있었다. 그러나 초기 제 조 소재의 경우 $\mathrm{W}$ 입자가 $\gamma(\mathrm{Ni}, \mathrm{Fe})$ 상으로부터 분리된 흔적이 나타났으며 열처리된 소재의 $\mathrm{W}$ 상은 변형 도중 깨 진 듯한 흔적이 관찰되었다.

후 열처리가 W-7Ni-3Fe의 변형 거동에 미치는 영향을 보 다 상세히 알아보고자 파단된 시편의 단면을 관찰하였으며 이를 그림 7에 도시하였다. 여기서 그림 7(a), (b), (c)는 초 기 소재 파단면의 단면이며 그림 7(d), (e), (f)는 열처리된

Table 1. Tensile property comparison of MIMed W-7Ni-3Fe materials and others manufactured materials by different processes.

\begin{tabular}{ccccc}
\hline & $\begin{array}{c}\text { Yield Strength } \\
{[\mathrm{MPa}]}\end{array}$ & $\begin{array}{c}\text { Ultimate Tensile Strength } \\
{[\mathrm{MPa}]}\end{array}$ & $\begin{array}{c}\text { Elongation } \\
{[\%]}\end{array}$ & Reference \\
\hline As-fabricated (MIM) & 698.3 & 760.8 & 2.4 & \\
Heat-treated (MIM) & 714.0 & 960.0 & 20.3 & \\
LPS & 593 & 914 & 31 & 16 \\
Microwave sintering & 630 & 922 & 19.7 & 18 \\
Cold work & 715 & 810 & 17 & 17 \\
CIP & 628 & 858 & 17 & 19 \\
Gelcasting & 622 & 917 & 17 & 19 \\
\hline
\end{tabular}



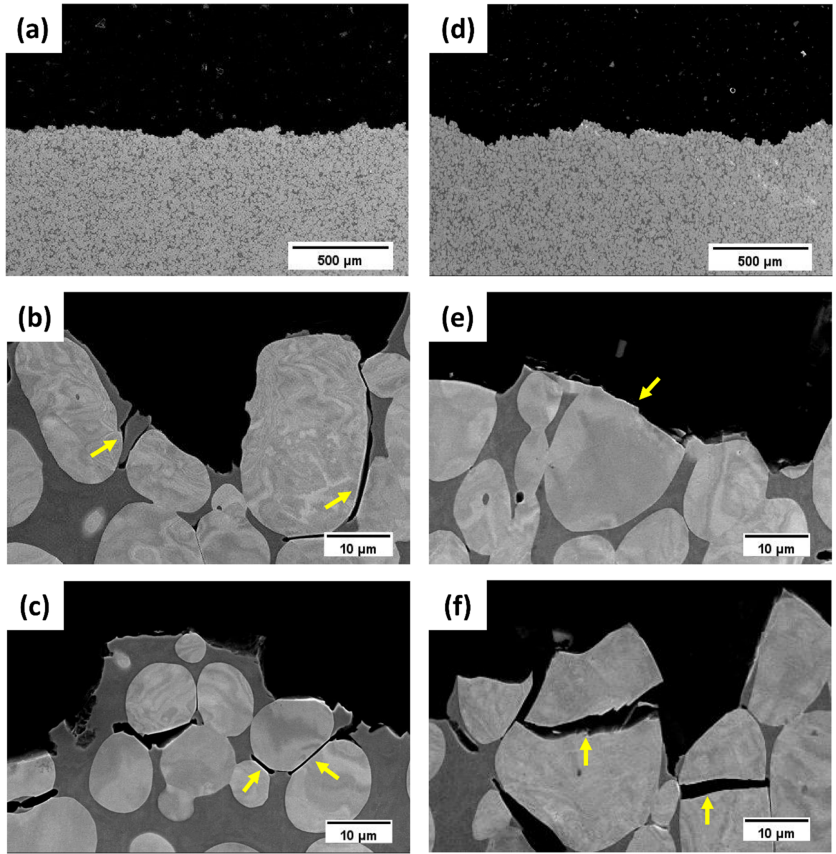

Fig. 7. SEM cross-sectional observation results: (a, b, c) asfabricated and $(\mathrm{d}, \mathrm{e}, \mathrm{f})$ heat-treated specimens after tensile tests.

소재의 단면이다. 관찰 결과 초기 소재의 경우 주된 균열이 $\mathrm{W}$ 상과 $\gamma(\mathrm{Ni}, \mathrm{Fe})$ 상의 계면을 따라 진전되는 반면 열처리 된 소재의 경우 주된 균열이 $\mathrm{W}$ 상을 가로지르며 진전되는 것을 확인할 수 있었다. 또한 초기 소재에 생성된 이차균열 은 $\mathrm{W}$ 상과 $\gamma(\mathrm{Ni}, \mathrm{Fe})$ 상 또는 $\mathrm{W}$ 상과 $\mathrm{W}$ 상 계면을 따라 형성된 것을, 열처리된 소재에 생성된 이차균열은 대부분 구 형의 $\mathrm{W}$ 상 내부를 따라 진행된 것을 알 수 있었다. 상기 결과들을 통해 W-7Ni-3Fe 합금에 추가적으로 열처리를 수 행할 시 $\mathrm{W}$ 상과 $\gamma(\mathrm{Ni}, \mathrm{Fe})$ 상의 결합력이 향상되는 것을 유추할 수 있었는데 이는 열처리 과정 중 결정립계에 존재 하는 잔류 수소가 제거되었기 때문으로 사료된다. 일반적으 로 수소 분위기에서 소결을 수행하여 제조된 $\mathrm{W}-7 \mathrm{Ni}-3 \mathrm{Fe}$ 합 금의 경우 결정립계에 잔류 수소가 존재하게 되는데 이러한 잔류 수소는 합금의 기계적 특성을 저하시킨다고 알려져 있 다. Yoon 등[20]은 텅스텐 중합금의 경우 $1000{ }^{\circ} \mathrm{C}$ 이상의 고온, 진공 분위기에서 열처리를 수행함에 따라 상간 계면 에 존재하는 잔류 수소가 제거되는 것을 확인한 바 있다. 또한 Penrice 등[21]은 $1000{ }^{\circ} \mathrm{C}$ 의 고온 열처리 후 퀜칭하 게되면 잔류 수소가 제거될 뿐만 아니라 W-Fe 또는 W-Ni 로 이루어진 금속간 화합물을 효과적으로 제어할 수 있어 상 간 계면에 불순물 석출을 방지할 수 있는 것으로 보고한 바 있다. 즉 본 연구에서 제조한 초기 소재와 열처리된 소 재가 유사한 상 분율 및 기공도를 나타내고 있음에도 불구
하고 열처리된 소재의 기계적 특성이 매우 높게 나타난 것 은 $1000{ }^{\circ} \mathrm{C}$ 이상의 온도에서 열처리 후 퀜칭함에 따라 잔 류 수소가 제거되고 일부 생성될 수 있는 금속간 화합물을 석출시키지 않아 계면 결합력이 향상되었기 때문으로 사료 된다.

\section{4. 결 론}

본 연구에서는 MIM 공정을 이용하여 $\mathrm{W}-7 \mathrm{Ni}-3 \mathrm{Fe}$ 텅스 텐 중합금을 제조하였다. 이와 함께 미세조직 및 기계적 특성에 미치는 열처리의 영향에 대해 조사했으며 다음과 같은 결론을 얻었다.

(1) 미세조직 관찰 결과, 두 소재 모두 $\mathrm{W}$ 상과 $\gamma(\mathrm{Ni}$, $\mathrm{Fe}$ ) 상으로 구성되어 있는 것을 알 수 있었다. 초기 소재 에서는 미세 기공이 약 $0.06 \%$ 로, 열처리된 소재의 경우 약 $0.04 \%$ 로 나타났다.

(2) 기계적 특성 평가를 위해 비커스 경도 측정 결과, 초기 소재와 열처리된 소재의 경도는 각각 363.7 , $387.2 \mathrm{Hv}$ 로 나타났다. 상온 인장 시험 결과, 초기 소재의 경우 항복 강도는 $698.3 \mathrm{MPa}$, 최대 인장 강도는 $760.8 \mathrm{MPa}$, 연신율은 $2.4 \%$ 로 측정되었으며, 열처리된 소재 의 경우 항복 강도는 $714.0 \mathrm{MPa}$, 최대 인장 강도는 $960.0 \mathrm{MPa}$, 연신율은 $20.3 \%$ 로 나타났다. 즉, 열처리 이후 강도 및 연신율의 인장 특성이 모두 우수해지는 것을 알 수 있었다.

(3) 파단면 관찰 결과, 초기 소재는 대부분의 균열이 $\mathrm{W}$ 상과 $\gamma(\mathrm{Ni}, \mathrm{Fe})$ 상 계면을 따라 형성되었으며, 열처리된 소재는 $\mathrm{W}$ 상 내부를 따라 균열이 진전된 것을 확인했다. 이를 통해 열처리 후 $\mathrm{W}$ 상과 $\gamma(\mathrm{Ni}, \mathrm{Fe})$ 상의 계면 결합 력이 우수해지는 것을 알 수 있었다.

\section{REFERENCES}

1. Y. S. Zu, Y. H. Chiou, and S. T Lin, J. Mater. Eng. Perform. 5, 609 (1996).

2. S. H. Hong, S.-J. L. Kang, and D. Y. Yoon, Korean J. Met. Mater. 29, 925 (1991).

3. N. V. Minh, Y. Konyukhov, G. Kanurakaran, D. Ryzhonkov, T. Duong, S. Kotov, and D. Kuznetson, Met. Mater. Int. 23, 532 (2017).

4. H. T. Turong, Y. H. Kim, and M. S. Lee, Korean J. Met. Mater. 55, 405 (2017).

5. T. S. Wei and R. M. German, Int. J. Powder. Metall. 24, 327 (1988). 
6. R. M. German, Powder Injection Molding, MPIF, Princeton, NJ (1990).

7. Y. A. Joo, Y. K. Kim, T. S. Yoon, and K. A. Lee, Met. Mater. Int. 24, 371 (2018).

8. Y. A. Joo, Y. K. Kim, T. S. Yoon, and K. A. Lee, Korean J. Met. Mater. 56, 342 (2018).

9. S. C. Yang and R. M. German, Metall. Trans. A 22A, 786 (1991).

10. Y. WU, R. M. German, B. Marx, P. Suri, and R. Bollina, J. Mater. Sci. 38, 2271 (2003).

11. J. Fan, S. Liang, X. Qu, and B. Huang, J. Mater. Process. Tech. 137, 177 (2003).

12. B. Huang, J. Fan, and X. Qu, J. Mater. Sci. Technol. 17, 673 (2001).

13. J. Fan, X. Qu, B. Huang, and X. Qu, T. Nonferr. Metal. Soc. 10, 794 (2000).
14. B. Huang, X. Qu, Z. Zou, and J. Fan, Int. J. Refract. Met. H. 19, 73 (2001).

15. T. K. Kang, E. -Th. Henig, and G. Petzow, Korean J. Met. Mater. 20, 775 (1982).

16. A. Bose, D. Sims, and R. M. German, Metall. Trans. A 19, 487 (1988).

17. V. Srikanth and G. S. Upadhyaya, J. Mater. Sci. Lett. 7, 195 (1988).

18. C. Zhou, J. Yi, S. Luo, Y. Peng, L. Li, and G. Chen, J. Alloy. Compd. 482, L6 (2009).

19. A. Panchal, U. R. Kiran, T. K. Nandy, and A. K. Singh, Metall. Mater. Trans. A 49A, 2084 (2018).

20. H. K. Yoon, S. H. Lee, S.-J. L. Kang, and D. N. Yoon, J. Mater. Sci. 18, 1374 (1983).

21. T. W. Penrice and J. Bost, U.S Patent, 4762559 (1988). 